\title{
The role of metalloproteinase and hypoxia conditions in endometrial cells and embryo implantation
}

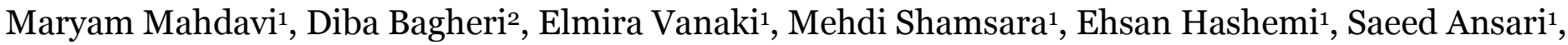 \\ Mojtaba Dashtizad ${ }^{1}$, Morteza Daliri Joupari1,** \\ ${ }^{1}$ Department of Animal Biotechnology, National Institute of Genetic Engineering and Biotechnology (NIGEB), Tehran, Iran \\ ${ }^{2}$ Department of Genetics, Faculty of Biological Sciences, Tarbiat Modares University, Tehran, Iran
}

\begin{abstract}
In the process of implantation, metalloproteinase enzymes play a key role in basement membrane degradation and endometrial extracellular matrix. The activity of these enzymes is impeded by binding Tissue Inhibitors of Metalloproteinase (TIMP). The oxygen concentration in the mammalian uterus at the time of implantation is about 2-5\%. It is seen that the imposition of hypoxia on cancer cells increases the expression of metalloproteinase enzymes and reduces the expression of metalloproteinase inhibitors, resulting in increased cell invasion. To know the effect of Hypoxia-Inducible Factor (HIF) and other related factors, we decided to evaluate hypoxic conditions on endometrial epithelial cells of the uterus and the role of matrix metalloproteinases (MMPs) on angiogenesis and invasion of the embryo during implantation. In this study, human and mouse endometrial epithelial cells were incubated for 24-48 hours in hypoxic conditions. Subsequently, the expression level of TIMP-1 was measured in mouse and human epithelial cells by Real-Time PCR technique. The cell viability in hypoxic conditions was evaluated by MTT assay. Our results demonstrated that hypoxia reduced the quantitative gene expression of TIMP-1 in the human and mouse endometrial epithelial cells compared to the control group. It can be concluded that applying hypoxic conditions by reducing the TIMP-1 expression and consequently increasing MMP expression, may improve the embryo implantation rate.
\end{abstract}

Keywords: Implantation, Embryo, Hypoxia, TIMP-1, MMPs

\section{Introduction}

Implantation is an essential process to develop the embryo, in which the embryo attaches to the outer layer of the uterus and then invades the uterine endometrium ready to accept it in several steps [1], including blastocyst opposition from Zona Pellucida, blastocyst adhesion to the uterine epithelium, embryo invasion to stromal cells and angiogenesis. The implantation success depends on the ability of the embryo to degrade the basement membrane of the uterine epithelium and invade the uterine stroma. Several major factors are involved in this process,

\section{* Corresponding author:}

Dr. Morteza Daliri Joupari, Ph.D

Department of Animal Biotechnology, NIGEB, Tehran, Iran

Tel/Fax: +98 2144580395

Email: daliri@nigeb.ac.ir

http://orcid.org/oooo-0001-9465-7983

Received: October, 07, 2020

Accepted: November, 11, 2020 including extracellular matrix degradation enzymes. Degradation of endometrial extracellular matrix facilitates the trophectoderm invasion to the uterine epithelium; various proteinases play a key role in this degradation, with the emphasis on the importance of metalloproteinase [2]. These enzymes are divided according to substrate specificity, including collagenases, gelatinases, and stromelysins. Gelatinase B (gel B; also known as MMP-9) plays a significant role in implantation. The binding of tissue inhibitors impedes the activity of metalloproteinase enzymes $[3,4]$. According to in vivo studies, the regulation of the 
balance between metalloproteinase and inhibitors presented in the fetus and the uterus leads to trophoblast invasion into the decidual cells of the endometrium. The tissue inhibitors of metalloproteinase enzymes inhibit processes such as angiogenesis, metastasis, tumorigenesis, and cellular invasion, and include four subsets. In 1970, tissue inhibitors of metalloproteinase-1 (TIMP-1) secreted glycoprotein $(25-31 \mathrm{kDa})$ was purified as the first member of this family from human skin fibroblasts. In 1999 and 2000, TIMP-2 and TIMP-3 with a molecular weight of $21 \mathrm{kDa}$, and TIMP-4 with a molecular weight of $22 \mathrm{kDa}$ were identified [5]. TIMP- 1 and TIMP-2 are both soluble proteins and TIMP-3 is an insoluble protein that is attached to the extracellular matrix components [6]. The inhibitors have almost the same structure with two domains in mammals, $\mathrm{N}$-terminal (125 amino acids) and C-terminal (65 amino acids) [7]. Their inhibitory activity occurs by binding the $\mathrm{N}$ terminal domain to the catalytic site of metalloproteinase enzymes [8]. The affinity of TIMP-1 to MMP-9 and TIMP-2 to MMP-2 is higher than other enzymes.

TIMP-1, TIMP-2, and TIMP-3 are expressed throughout the menstrual cycle in luminar and glandular epithelial cells, veins, and endometrial stromal cells [9]. The TIMP-1 mRNA level is higher during the secretive and menstrual phase compared to the proliferative phase. The TIMP-2 mRNA level is almost constant throughout the cycle. The TIMP-3 mRNA level is higher in the late secretive and menstrual phase compared to the early secretive and proliferative phase. The expression of TIMP-3 in comparison with TIMP-1 and -2 has a variety of variations throughout the cycle [10]. Vascular endothelial growth factor (VEGF) is one of the most important angiogenesis regulators that plays a significant role in the implantation process [11], followed by the formation of the placenta. The highest expression of this factor is affected by the estrogen and progesterone as well as hypoxic conditions in the secretive phase [12], in other words, in the implantation window. Evidence suggests that VEGF increases the expression of metalloproteinase secreted by blastocyst [13] and reduces the expression of metalloproteinase inhibitors presented in the uterine endometrium [14]. In hypoxic conditions, hypoxiainducible factor (HIF) is activated which contains two subunits of HIF1 $\alpha$ and HIF1 $\beta$ [15]. HIF1 $\alpha$ enters the nucleus and attaches to HIF1 $\beta$ and finally by binding to Hypoxia Responsive Elements (HRE) located in the promoter region of the target gene, leads to transcript from the desired gene. The HRE sequence is located in the promoter region of the VEGF and matrix metalloproteinases (MMPs) genes. In other words, the HIF factor is activated in hypoxic conditions and plays a role in processes such as angiogenesis and invasion, expressed by VEGF and MMPS, respectively. In studies on cancer, it has been seen that the expression of TIMP has decreased in hypoxic conditions [16]. Given that VEGF has an inhibitory effect on TIMPs expression, it can be said that hypoxic conditions can indirectly reduce the TIMPs expression. To know the effect of HIF and other related factors, we decided to evaluate hypoxic condition on endometrial epithelial cells of uterus and the role of MMPs on angiogenesis and invasion of the embryo during implantation.

\section{Materials and Methods}

2.1 Preparation and culture of endometrial (uterine) epithelial cells

All chemicals were obtained from Sigma-Aldrich (USA); otherwise, they are specified within the text. Human endometrial epithelial cells (C10128) were obtained from the Iranian Biological Resource Center (IBRC), Tehran, Iran. Cells were maintained in DMEM/F12 medium supplemented with 10\% FBS. When cultured cells reached 80-90\% confluency, the cultured flask was sub-cultured with $0.25 \%$ Trypsin/EDTA solution. To obtain mouse endometrial epithelial cells, pseudopregnant mice were used. To this end, a number of female mice were mated with vasectomized male mice and positive vaginal plaque were detected on the next morning. After 5-6 days, when the uterus had a thicker wall, the mice were euthanized by cervical dislocation and then dissected. Animal experiments was reviewed and approved by the local Ethical Committee (IR.NIGEB.EC.1394.8.10.A). Mice were group housed 4-5 to a cage on a $12 \mathrm{~h}$ light/12 $\mathrm{h}$ dark cycle with food and water available ad libitum in a temperaturecontrolled room $\left(22 \pm 1{ }^{\circ} \mathrm{C}\right)$. The cells were isolated from the internal surface of the fallopian tubes, using 0.25\% Trypsin/EDTA solution and thus a uniform solution of cells was obtained. Then, the overall cell volume was evenly distributed between two flasks, containing DMEM/F12 medium and 10\% FBS. The cells were examined for viability and uniformity 
dispersion using an inverted microscope (Nikon, Eclipse-Ts-100) and finally incubated. After the bottom of the flask is covered by about 70 to $80 \%$, the cells were passaged in three similar flasks to create enough space for growth on a culture dish.

\subsection{Flow cytometry}

Since verified human endometrial epithelial cells were purchased from IBRC, the evaluation of cell surface markers in contrast to mouse cells did not carry out. Mouse endometrial epithelial cells were identified and characterized based on cell surface markers. The flow cytometry performed at the national blood bank, Tehran, Iran, briefly, $10^{6}$ cells at passage 3 were cast in $1.5 \mathrm{ml}$ Falcon. Cells were incubated with primary antibodies of surface markers CD44 (Dako, Denmark) and CD54 (Dako, Denmark), and the process was continued by exposure to the FITC-conjugated secondary antibody at $4{ }^{\circ} \mathrm{C}$ in a dark place for $30 \mathrm{~min}$. Readings were performed with flow cytometry (Partec Cy-Flow), and the results were analyzed using FloMax software.

\subsection{MTT cell proliferation assay}

MTT assay was performed to determine the effect of hypoxia on growth and proliferation of cells using $3^{-}$ (4, 5-Dimethylthiazol)-2, 5-diphenyltetrazolium bromide (MTT). In each well of the 96-well plate, 10,000 cells $/ \mathrm{ml}$ were cultured in triplicate. Plates were exposed to hypoxic conditions $\left(5 \% \mathrm{O}_{2}\right)$ at $37{ }^{\circ} \mathrm{C}$ with $85 \%$ humidity in an incubator for 24 and 48 hours. After the incubation time, the supernatant of each well was removed and replaced with $10 \mu \mathrm{l}$ of MTT at a concentration of $5 \mathrm{mg} / \mathrm{ml}$ in a phosphate buffer solution. Further incubation for 4 hours, the supernatant was removed and formazan crystals were dissolved with $50 \mu \mathrm{l}$ of DMSO. After the complete dissolution of crystals, the OD of each well was read at $580 \mathrm{~nm}$ versus the DMSO control solvent by the enzyme-linked immunosorbent assay (ELISA) Reader.

\subsection{Hypoxic condition and RNA extraction}

Human and mouse endometrial cell suspension was made separately; 10,000 cells/ml were cultured in triplicate in different 96-well plates. Plates were incubated at $37^{\circ} \mathrm{C}$ in an incubator having the hypoxic condition $\left(5 \% \mathrm{O}_{2}\right)$ with $85 \%$ humidity and control plates were incubated at $37{ }^{\circ} \mathrm{C}$ having $5 \% \mathrm{CO}_{2}$ with
$85 \%$ humidity for 24 and 48 hours for gene analysis evaluation. Total RNA was extracted from cultured cells in hypoxic and control group in two different incubation times by Total RNA Extraction Kit (Roche Co., Germany), in accordance with the manufacturer's protocol, extracted RNA was then synthesized to cDNA using cDNA kits (K-2101, Bioneer, S. Korea). To verify the accuracy of synthesized cDNA, PCR with a final volume of $15 \mu \mathrm{l}$ was performed using a PCR master mix (Ampliqon 190301). Finally, the gene expression was analyzed by Real-Time RT-PCR technique. The reaction was prepared in a volume of $20 \mu \mathrm{l}$ using Maxima SYBR Green qPCR Master Mix kit (Fermentas, USA) as the following thermal profile: 95 ${ }^{\circ} \mathrm{C}$ for $10 \mathrm{~min}, 4 \mathrm{O}$ cycles of $95^{\circ} \mathrm{C}$ for 20 seconds, 57.8 ${ }^{\circ} \mathrm{C}$ for 30 seconds, and $72{ }^{\circ} \mathrm{C}$ for 20 seconds. Data were standardized to the corresponding ovine GAPDH (Glyceraldehyde 3-phosphate Dehydrogenase) level. Specific primers (TIMP-1 for human and mouse) were designed using the Beacon Designer 7 software, as listed in Table 1. 


\subsection{Statistical analysis}

All experiments were repeated in triplicate and results were expressed as means \pm standard deviation. After obtaining the $\mathrm{Ct}$ of genes from different treatments, the data was calculated to obtain the expression level by the Livac method and then analyzed by SPSS 16.0 software using one-way ANOVA and Duncan's test for data comparison. $\mathrm{P}<0.05$ was considered significant.

\section{Results}

\subsection{Surface markers}

Results obtained from flow cytometry showed that CD44 and CD54 levels on the surface of mouse endometrial epithelial cells were $75.46 \%$ and $51.94 \%$, respectively (Figure 1).

\subsection{Effect of hypoxic conditions on cell viability}

The growth and proliferation of human and mouse endometrial epithelial cells were assessed by MTT assay after 24 and 48 hours in hypoxic conditions. The viability of mouse endometrial epithelial cell proliferation in hypoxic conditions (5\% oxygen) compared to $20 \%$ oxygen was reduced by $18.61 \%$, and the viability of human endometrial epithelial cells in hypoxic conditions was also reduced by $16.83 \%$. The results obtained (the number of cells) are shown in Figures 2. The data is derived from three replications.

\subsection{Relative expression of TIMP-1}

PCR product on gel electrophoresis showed a 152bp band of Timp-1 in mouse sample and a 156-bp band of Timp-1 in the human sample (Figure 3). These figures confirm the accuracy of the initial stages of the test, showing the cDNA synthesis and proper performance of primers at $61^{\circ} \mathrm{C}$.

\subsection{Decrease in expression of TIMP-1}

Since the SYBR Green dye used in the reaction is a non-specific detector and binds to any doublestranded DNA, a melting curve is required to ensure the proper and specific proliferation. As shown in Figure 4, the expression of TIMP-1 was significantly reduced after 24 hours of incubation in hypoxia (6.5fold decrease in expression) as well as in 48 hours of hypoxia (0.412-fold decrease in expression) as compared to the control group. The result also show
TIMP-1 gene expression in the human endometrial epithelial cells was significantly decreased in 24 hours of hypoxia (0.70-fold decrease in expression) as well as in 48 hours of hypoxia (0.31-fold decrease in expression) as compared to the control group.
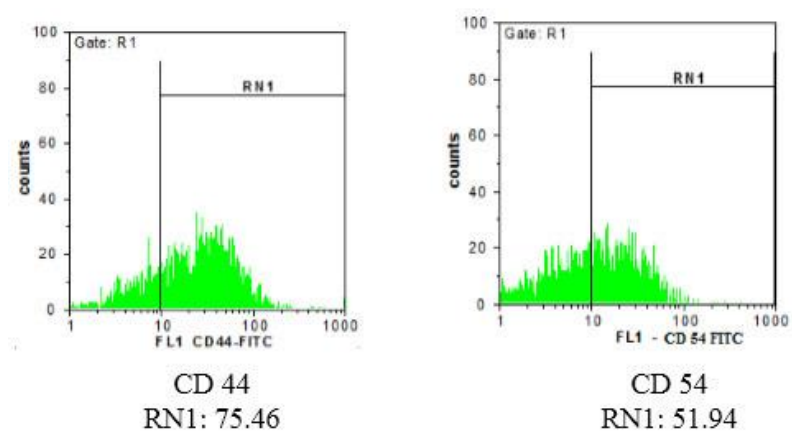

Figure 1. Surface markers of endometrial epithelial cells in the mouse uterus

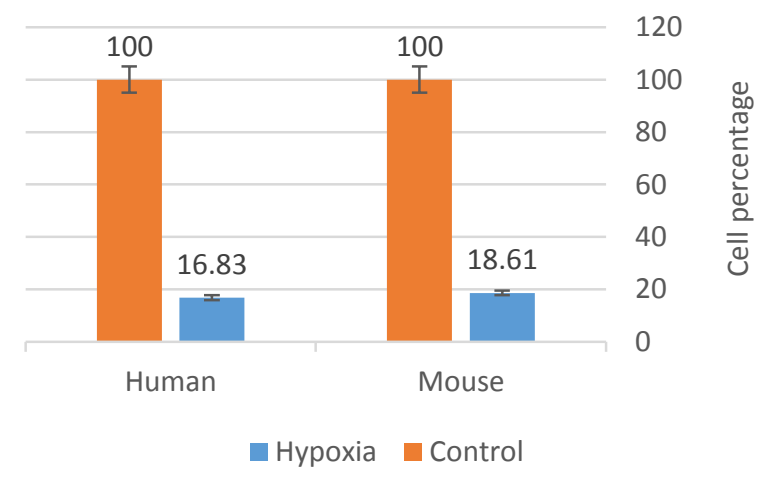

Figure 2. Comparison of the number of mouse and Human uterine endometrium cells in hypoxic conditions after 24 and 48 hours compared to normal conditions

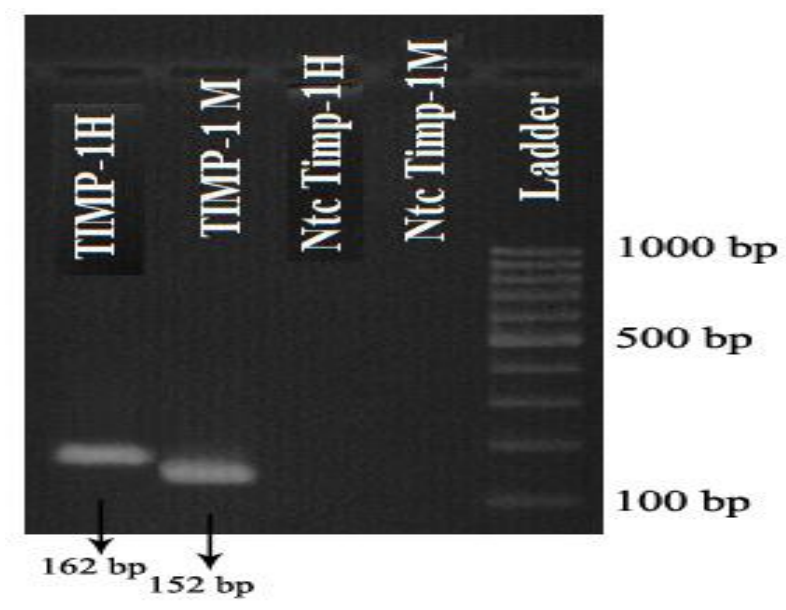

Figure 3. Gel electrophoresis 


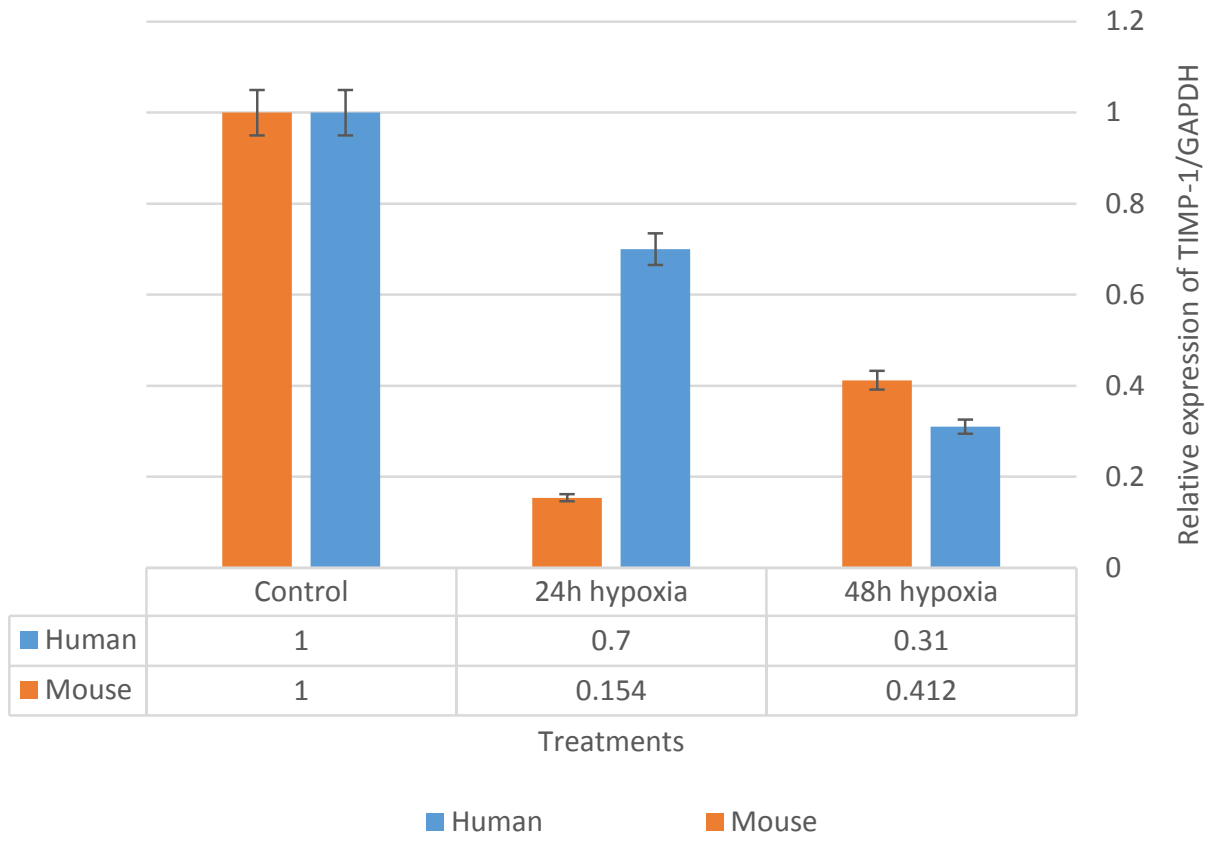

Figure 4. Hypoxic effect on TIMP-1 gene expression in epithelial cells of the Human and mouse uterine endometrium after 24 and 48 hours

\section{Discussion}

Previous studies on surface markers showed that CD44 and CD54 are presented in the mouse endometrial epithelial cell surface throughout the cycle [17]. According to our flow cytometry results, CD44 and CD54 were found on $75.46 \%$ and $51.94 \%$ of cells surface, respectively; so it can be concluded that isolated cells were the mouse endometrial epithelial cells. Results on the viability of PC12 cells (derived from rat kidney) indicated a reduction by $14 \%$ under hypoxic conditions than normal conditions [18]. Our cell viability in hypoxic conditions (5\% oxygen) also showed a decrease of $18.16 \%$ in mouse and $16.83 \%$ in human endometrial cells in comparison with $20 \%$ oxygen. As a result, it can be said that hypoxia has a slightly destructive effect on cell viability. In fact, oxygen depletion can be considered as the environmental stress that changes intracellular functions and pathways.

Embryonic development depends on the immediate access of the embryo to the maternal blood flow. Implantation is the first step in achieving this capability. The ability of embryonic invasion into endometrial tissue is the most important means to achieve this goal, and invasion needs to secrete extracellular matrix (ECM) degrading enzymes. Studies on the implantation process showed that the most important proteases involved in this process were MMPs and serine proteases, in which MMP9 and urokinase plasminogen activator (UPA) had the highest expression at the time of implantation [19]. The advancement of laboratory techniques such as RT-PCR, immunocytochemistry, plasminogen-casein zymography demonstrated that the UPA expression was increased in medium from 4-8 days after fertilization [20]. The zymography test also showed an increase in the protein in the medium on the 6-9th day, this can be attributed to the increased expression of this protein when leaving the Zona, which predisposes the blastocyst for implantation [20].

The highest MMP9 expression in the mouse trophoblastic cells was observed on the day of 4.5-7.5 as parallel with the time of implantation, indicating the importance of this enzyme in trophoblast invasion. Inhibition of this enzyme expression reduces trophoblast invasion [21]. Also, this enzyme expression level at in vitro embryos is less than at in vivo ones. Given its importance in implantation, it can be considered as one of the causes of implantation reduction in laboratory conditions [22]. Observations suggest that inhibiting this enzyme by TIMP-1 could prevent adhesion of the mouse embryo to the uterus. The expression of TIMP-1 and TIMP-2 is increased in the stroma and basement membrane within 15-24 
days of the menstrual cycle, the time of maximal progesterone levels. This plays a key role in protecting the uterine endometrial tissue against proteins secreted from the embryo (MMPs) but decreased the activity of TIMPs during implantation due to the presence of inhibitory factors such as cytokines, especially leukemia inhibitory factor (LIF), and decreased progesterone receptors, resulting in an embryo invasion into the uterine endometrial epithelium [23]. On in vivo, none of the human tissues, except for the alveoli, is exposed to high concentrations of oxygen. Measuring the oxygen content of the female reproductive system also shows that gametes and embryos have never been exposed to oxygen concentrations of more than 10\% [24]. For example, the oxygen content is between $2 \%$ to $6 \%$ in the rabbit oviduct and about $8 \%$ in the hamster and rhesus macaque oviducts [25].

The embryo encounters an oxygen gradient when passing from the fallopian to the uterus so that the oxygen pressure in the uterus is lower than other parts of the reproductive system and the amount of oxygen is lower (3.5\% to 5\%) during implantation [26]. The previous report has shown that no studies have ever been done on the expression of TIMP-1 gene in uterine endometrial epithelial cells under hypoxic conditions, and the evaluations only focus on the cultivation of other cells. Changes in the oxygen level cause new reactions in the cell to create the ability to cope with new conditions. Adaptation with hypoxia involves a wide range of responses, such as changing the expression of genes, altering metabolic functions and changing the activity of ion channels; all of which are essential for cell viability. The ability of cells to respond to oxygen depends on the activation of the family of transcription factors called HIF that binds to HRE in the promoter region of the target gene to initiate transcription. The significance of this factor is where the main transcription factor is in response to hypoxia and transcribes over 40 genes, including glucose transporters, glycolytic enzymes, factors involved in angiogenesis, and other genes enhancing oxygenation [27]. The purification of DNA-binding factors revealed that HIF consists of a heterodimer protein complex comprising HIF1_ $\alpha$ and HIF1_ $\beta$. HIF stays in the cell only when the cell is cultured in hypoxia. The level of this protein increases with oxygen reduction slowly from $20 \%$ to $7 \%$ and reaches its maximum at $5 \%$. The rapid degradation process does not occur in the Beta subunit and this subunit has a permanent expression [28]. The promoter of this factor is rich in GCand it has a very low expression in most cells of the body, but its expression is greatly increased in hypoxia [29]. Two subunits of HIF1- $\alpha$ and HIF2- $\alpha$ accumulate rapidly in hypoxia. The reason for this is the stability of these two subunits. The HIF is attached to DNA within the CGTG sequence $(\mathrm{A} / \mathrm{G})$ in the HRE region, which in turn increases the expression of the target gene. Although the most important factor in regulating HIF1- $\alpha$ is the amount of oxygen, research has shown that this transcription factor is affected by other factors, such as nitric oxide, cytokines, and growth factors.

The study highlighted the role of this factor in embryonic development because the female reproductive system has an environment rich in growth factors, cytokines, reducing molecules, and oxygen. This strengthens the theory that the activation of this factor on in vitro fertilization (IVF) causes a simulation of the conditions in which the embryo is in its normal state [30]. Misregulation or overexpression of this factor by hypoxia or genetic changes is effective in the development of cancer and tumor invasion [31]. As a result of the observations, HIF1a is considered to be the most important factor in regulating gene expression in hypoxia conditions.

Some genes containing this particular region in their promoter are those involved in angiogenesis, energy metabolism, erythropoietin, and cell proliferation and invasion [30]. The HRE sequence is located in the promoter region of the VEGF and MMPs genes. In other words, the HIF factor is activated under hypoxia and it is involved in some vital processes of the body, such as angiogenesis and invasion, by expressing VEGF and MMPS respectively.

VEGF is one of the most exclusive regulators of angiogenesis that is expressed under the influence of estrogen, progesterone and hypoxia in implantation. Jung et al. showed that the LIF cytokine (maximum expression of LIF in the uterine epithelium cells in implantation as well as in the embryo before implantation) under hypoxia, activates the STAT3 transcription factor that in the interaction with the HIF factor, is associated with the increased expression of the VEGF factor [32].

On the other hand, Pufe et al. reported that VEGF, as an autocrine growth factor, under cartilage hypoxia, 
increases the MMP expression and decreases the TIMP-1,2 expression. In fact, the balance between the enzyme and the inhibitor is eliminated [33]. Another study in 2001 demonstrated that the cultivation of MCF-7 and HTR8-S/Vneo cells (which is a human trophoblast cell line) under hypoxia for 24 hours, decreased TIMP-1 expression and increased MMP-9 expression, thereby increased cell invasion [16].

The results of this study showed that TIMP-1 gene expression is decreased in 24 and 48-hour hypoxia samples, compared to control endometrial epithelial cells of human and mice. Therefore, it can be concluded that hypoxia reduces the expression of genes involved in implantation. In short, it can be said that applying hypoxic conditions reduces the expression of genes involved in invasion. Given the importance of invasion in the implantation process as the most important stage in pregnancy, this treatment will improve this phase.

\section{Author Contributions}

All authors contributed equally to this manuscript, and approved the final version of manuscripts.

\section{Conflict of Interests}

The authors declare that they have no conflicts of interest.

\section{Ethical declarations}

Animal experiments was reviewed and approved by the local Ethical Committee of National Institute of Genetic Engineering and Biotechnology (NIGEB) (IR.NIGEB.EC.1394.8.10.A).

\section{Financial Support}

The authors would like to acknowledge the National Institute of Genetic Engineering and Biotechnology (NIGEB, Tehran, Iran) for technical and financial support under contract grant number 941113-I-557.

\section{References}

1. Koot YE, Macklon NS. Embryo implantation: biology, evaluation, and enhancement. Curr Opin Obstet Gynecol. 2013; 25(4):274-9.

2. Bischof P, Campana A. A putative role for oncogenes in trophoblast invasion? Hum Reprod. 2000; 15 Suppl 6:51-8.

3. Gaddy-Kurten D, Hickey GJ, Fey GH, Gauldie J, Richards JS. Hormonal regulation and tissue-specific localization of alpha 2macroglobulin in rat ovarian follicles and corpora lutea. Endocrinology. 1989; 125(6):2985-95.
4. Dajee M, Kazansky AV, Raught B, Hocke GM, Fey GH, Richards JS. Prolactin induction of the alpha 2-Macroglobulin gene in rat ovarian granulosa cells: stat 5 activation and binding to the interleukin-6 response element. Mol Endocrinol. 1996; 10(2):17184 .

5. Nagase H, Woessner JF, Jr. Matrix metalloproteinases. J Biol Chem. 1999; 274(31):21491-4.

6. Määttä M, Soini Y, Liakka A, Autio-Harmainen H. Localization of MT1-MMP, TIMP-1, TIMP-2, and TIMP-3 messenger RNA in normal, hyperplastic, and neoplastic endometrium. Enhanced expression by endometrial adenocarcinomas is associated with low differentiation. Am J Clin Pathol. 2000; 114(3):402-11.

7. Williamson RA, Marston FA, Angal S, Koklitis P, Panico M, Morris HR, et al. Disulphide bond assignment in human tissue inhibitor of metalloproteinases (TIMP). Biochem J. 1990; 268(2):267-74.

8. Staun-Ram E, Shalev E. Human trophoblast function during the implantation process. Reprod Biol Endocrinol. 2005; 3:56.

9. Kovalenko VL, Kazachkov EL, Voropaeva EE, Kazachkova EA. [The characteristics of the epithelium and endometrial extracellular matrix in miscarriage during early pregnancy associated with chronic endometritis]. Arkh Patol. 2009; 71(5):403.

10. Goffin F, Munaut C, Frankenne F, Perrier D'Hauterive S, Béliard A, Fridman V, et al. Expression pattern of metalloproteinases and tissue inhibitors of matrixmetalloproteinases in cycling human endometrium. Biol Reprod. 2003; 69(3):976-84.

11. Smith SK. Angiogenesis and implantation. Hum Reprod. 2000; 15 Suppl 6:59-66.

12. Shifren JL, Tseng JF, Zaloudek CJ, Ryan IP, Meng YG, Ferrara $\mathrm{N}$, et al. Ovarian steroid regulation of vascular endothelial growth factor in the human endometrium: implications for angiogenesis during the menstrual cycle and in the pathogenesis of endometriosis. J Clin Endocrinol Metab. 1996; 81(8):3112-8.

13. Li S, Cao Y, Zhang J, Tian Y, Zheng X, Duan E. Effects of vascular endothelial growth factor on MMPs during embryo implantation in mice. Chinese Sci Bull. 2002; 47(24):2071-4.

14. Dong JC, Dong H, Campana A, Bischof P. Matrix metalloproteinases and their specific tissue inhibitors in menstruation. Reproduction. 2002; 123(5):621-31.

15. Meade ES, Ma YY, Guller S. Role of hypoxia-inducible transcription factors 1alpha and 2alpha in the regulation of plasminogen activator inhibitor-1 expression in a human trophoblast cell line. Placenta. 2007; 28(10):1012-9.

16. Canning MT, Postovit LM, Clarke SH, Graham CH. Oxygenmediated regulation of gelatinase and tissue inhibitor of metalloproteinases-1 expression by invasive cells. Exp Cell Res. 2001; 267(1):88-94.

17. Singh H, Aplin JD. Adhesion molecules in endometrial epithelium: tissue integrity and embryo implantation. J Anat. 2009; 215(1):3-13.

18. Alvarez-Tejado M, Naranjo-Suarez S, Jiménez C, Carrera AC, Landázuri MO, del Peso L. Hypoxia induces the activation of the phosphatidylinositol 3-kinase/Akt cell survival pathway in PC12 cells: protective role in apoptosis. $\mathrm{J}$ Biol Chem. 2001; 276(25):22368-74. 


\section{Mahdavi et al.}

19. Nie GY, Butt AR, Salamonsen LA, Findlay JK. Hormonal and non-hormonal agents at implantation as targets for contraception. Reprod Fertil Dev. 1997; 9(1):65-76.

20. Martínez-Hernández MG, Baiza-Gutman LA, Castillo-Trápala A, Armant DR. Regulation of proteinases during mouse periimplantation development: urokinase-type plasminogen activator expression and cross talk with matrix metalloproteinase 9. Reproduction. 2011; 141(2):227-39.

21. Menino AR, Jr., O'Claray JL. Enhancement of hatching and trophoblastic outgrowth by mouse embryos cultured in Whitten's medium containing plasmin and plasminogen. $\mathrm{J}$ Reprod Fertil. 1986; $77(1): 159-67$.

22. Aflalo ED, Sod-Moriah UA, Potashnik G, Har-Vardi I. Expression of plasminogen activators in preimplantation rat embryos developed in vivo and in vitro. Reprod Biol Endocrinol. 2005; 3:7.

23. Curry TE, Jr., Osteen KG. The matrix metalloproteinase system: changes, regulation, and impact throughout the ovarian and uterine reproductive cycle. Endocr Rev. 2003; 24(4):428-65.

24. Mastroianni L, Jr., Jones R. Oxygen tension within the rabbit fallopian tube. J Reprod Fertil. 1965; 9:99-102.

25. CattJW, Henman M. Toxic effects of oxygen on human embryo development. Hum Reprod. 2000; 15 Suppl 2:199-206.

26. Fischer B, Bavister BD. Oxygen tension in the oviduct and uterus of rhesus monkeys, hamsters and rabbits. J Reprod Fertil. 1993; 99(2):673-9.

27. Iyer NV, Kotch LE, Agani F, Leung SW, Laughner E, Wenger $\mathrm{RH}$, et al. Cellular and developmental control of O2 homeostasis by hypoxia-inducible factor 1 alpha. Genes Dev. 1998; 12(2):149-62.

28. Lando D, Peet DJ, Whelan DA, Gorman JJ, Whitelaw ML. Asparagine hydroxylation of the HIF transactivation domain a hypoxic switch. Science. 2002; 295(5556):858-61.

29. Minet E, Ernest I, Michel G, Roland I, Remacle J, Raes M, et al. HIF1A gene transcription is dependent on a core promoter sequence encompassing activating and inhibiting sequences located upstream from the transcription initiation site and cis elements located within the 5'UTR. Biochem Biophys Res Commun. 1999; 261(2):534-40.

30. Déry MA, Michaud MD, Richard DE. Hypoxia-inducible factor 1: regulation by hypoxic and non-hypoxic activators. Int $J$ Biochem Cell Biol. 2005; 37(3):535-40.

31. Bos R, van der Groep P, Greijer AE, Shvarts A, Meijer S, Pinedo $\mathrm{HM}$, et al. Levels of hypoxia-inducible factor-1alpha independently predict prognosis in patients with lymph node negative breast carcinoma. Cancer. 2003; 97(6):1573-81.

32. Jung JE, Lee HG, Cho IH, Chung DH, Yoon SH, Yang YM, et al. STAT3 is a potential modulator of HIF-1-mediated VEGF expression in human renal carcinoma cells. Faseb j. 2005; 19(10):1296-8.

33. Pufe T, Harde V, Petersen W, Goldring MB, Tillmann B, Mentlein R. Vascular endothelial growth factor (VEGF) induces matrix metalloproteinase expression in immortalized chondrocytes. J Pathol. 2004; 202(3):367-74. 